\title{
Studies on electro-chemical corrosion of carbon fiber reinforced aluminium alloy AA7075
}

\author{
MADHURI DESHPANDE ${ }^{1, *}, \mathrm{~S}$ T VAGGE ${ }^{2}, \mathrm{~S}$ V S NARAYAN MURTY ${ }^{3}$, HARISHWAR KALE ${ }^{1}$ \\ and RAMESH GONDIL ${ }^{1}$ \\ ${ }^{1}$ Production Engineering Department, Vishwakarma Institute of Technology, Pune, India \\ ${ }^{2}$ Department of Metallurgy and Materials Science, College of Engineering Pune, Shivaji Nagar, Pune, India \\ ${ }^{3}$ Material Characterization, Vikram Sarabhai Space Center, Thiruvananthpuram, India \\ e-mail: madhuri.deshpande@ vit.edu; stv.meta@coep.ac.in; narayanamurty_susarla@vssc.gov.in; \\ harishwar.kale@vit.edu; rameshgondil33@gmail.com
}

MS received 13 June 2018; revised 27 September 2019; accepted 10 October 2019

\begin{abstract}
Carbon fiber reinforced AA7075 is known for good thermal properties and thus used as heat dissipating material. However, few such applications involve corrosive environments too, and hence there is a need to study the behavior of these composite materials under corrosive environment. In the present work, milled carbon fiber reinforced AA7075 composites were produced by vacuum hot pressing with varying amounts of milled carbon fibers. The relative densities of the composites were measured. SEM-EDS, TEM and XRD techniques were also employed for characterization. The composites were then characterized for electrochemical behavior in $3.5 \mathrm{wt} . \%$ aqueous $\mathrm{NaCl}$ solution by electrochemical polarization technique. Results showed that the corrosion potentials $\mathrm{E}_{\text {corr }}$ have shifted to more negative direction and thus showed increase in corrosion current density, leading to increase in corrosion rate with increasing vol.\% of carbon fibers. These results were complemented by SEM micrographs of the composites after corrosion test, which revealed that corrosion occurred at the interface of carbon fiber and matrix due to formation of galvanic coupling between carbon fiber and matrix. Thus, reduced corrosion resistance in composites as amount of fibers increases, is attributed to increase in number of galvanic cells that form at the interface.
\end{abstract}

Keywords. Carbon fibers; AA7075 alloy; metal matrix composites; corrosion; SEM/EDS.

\section{Introduction}

Non-metallic reinforcing materials such as $\mathrm{SiC}, \mathrm{Al}_{2} \mathrm{O}_{3}$, carbon fibers, graphite flakes, graphene and mica are incorporated in metals and alloys to result in MMCs, in order to selectively enhance the mechanical strength and wear resistance or to improve thermal properties. In recent commercial electronics, due to system miniaturization, increased power, higher functionality and higher calculating speed, large amount of heat gets generated in devices and hence thermal management has become very important $[1,2]$. Heat sinks transfer heat generated by electronic devices, often to air. For heat sinks as well as for electronic packaging, lighter materials with high conductivity and low Coefficient of Thermal Expansion (CTE) are the right choice. Pure metals like $\mathrm{Cu}, \mathrm{Al}, \mathrm{Au}$ and $\mathrm{Ag}$ or combinations of metals like $\mathrm{Cu}-\mathrm{Mo}$ and $\mathrm{Cu}-\mathrm{W}$ can be the candidates for such applications due to their good thermal conductivity.

*For correspondence

Published online: 01 November 2019
However, the CTE of these materials is very high (much higher than the semiconductor device to be packaged).

Further, their high density (excepting aluminium) and high cost are the other factors against their use. Therefore, innovative materials are mandated to satisfy emerging electronic cooling requirements. Aluminium based metal matrix composites (as they possess enhanced thermal properties with lower density) appear to be promising as the next generation thermal management materials [2].

Introduction of a second phase as reinforcement into a metallic matrix changes the electro-chemical behavior of the matrix materials. Such reinforcements may or may not make the material susceptible to corrosion. The tendency towards corrosion depends on (a) the combination of matrix material and reinforcement used, and (b) manufacturing method adopted for producing the composite [3-5]. It has been reported that the susceptibility of MMCs to corrosion in various environments is due either to galvanic reactions that occur between the reinforcements and the matrix, or to selective corrosion at the interface (because of the formation of new compounds) or to the defects at the interface, 
causing fissures which create probable areas for corrosion [6]. It has also been found out that most aluminium based MMCs have poorer corrosion resistance as compared to base alloys, due to break down of protecting film that is caused by the reinforcement phase.

Liquid metallurgy and powder metallurgy routes are commonly used by the researchers for producing carbon fiber reinforced aluminium metal matrix composites. Due to its ease and simplicity, liquid metallurgy route has been the choice of many researchers [7-9]. Low wettability of carbon fibers and the formation of $\mathrm{Al}_{4} \mathrm{C}_{3}$ at the interface of carbon fiber and matrix are the major constraints of this route, particularly because $\mathrm{Al}_{4} \mathrm{C}_{3}$ is detrimental to thermal properties, mechanical properties and corrosion resistance $[10,11]$. Nickel coating on carbon fibers has been adopted by some of the researchers to overcome the lack of wettability [11, 12]. Powder metallurgy is the alternative because this route almost fully eliminates the risk of formation of $\mathrm{Al}_{4} \mathrm{C}_{3}$ and is free of wettability related problems $[2,13]$.

Aluminum alloys have a natural, strong and thin oxide layer on the surface which protects them from pitting initiation. If this oxide layer breaks, aluminum alloy recovers by itself and generates newer passive film. In the case of particulate MMCs containing ceramic reinforcements (viz., oxides or carbides), this film breaks down leading to pitting and crevice corrosion of underlying substrate. With increase in the amount of reinforcement, sites for corrosion initiation may increase. In contrast, incorporation of carbon fibers or flakes improves the thermal properties, but the magnitude of their effect on corrosion resistance is yet to be established. Lack of such data was the stimulus behind this investigation.

In the present work, therefore, solid state powder metallurgy route was adopted for the production of AA7075 composites with different volume contents of milled carbon fibers. Characterization of their electro-chemical behavior was carried out through systematic and extensive Potentiodynamic corrosion tests. The findings have been substantiated by SEM, EDS and TEM studies.

\section{Experimental}

\subsection{Materials}

Aluminium alloy AA7075 in powder form (spherical shaped particles, average particle size $35 \mu \mathrm{m}$ ) formed the matrix material. The powder is purchased from AMPLE INC. Table 1 shows the chemical composition of AA7075.

The reinforcement material used was pitch-based, milled carbon fibers (DIALEADK $223 \mathrm{HM}$ grade, $10 \mu \mathrm{m}$ diameter and $200 \mu \mathrm{m}$ length, as per seller's specifications). These fibers were purchased from MITSUBISHI PLASTICS, INC. For satisfactory distribution of the carbon fibers in the matrix, low aspect ratio carbon fibers (aspect ratio 20) were chosen for this work. Figures 1(a) and (b) show the surface morphology of aluminium alloy powder and the carbon fiber, respectively. Density of the composites were evaluated by Archimedes principle. Table 2 gives the density values that were calculated by Rule of Mixture (ROM) and actual experimental values.

Table 1. Chemical composition of AA7075 powder [14].

\begin{tabular}{llllllllll}
\hline Element & $\mathrm{Cu}$ & $\mathrm{Mg}$ & $\mathrm{Zn}$ & $\mathrm{Si}$ & $\mathrm{Fe}$ & $\mathrm{Ti}$ & $\mathrm{Mn}$ & $\mathrm{Cr}$ & $\mathrm{Al}$ \\
\hline $\mathrm{wt} \%$ & 1.6 & 2.5 & 5.6 & 0.4 & 0.5 & 0.2 & 0.3 & 0.25 & Balance \\
\hline
\end{tabular}
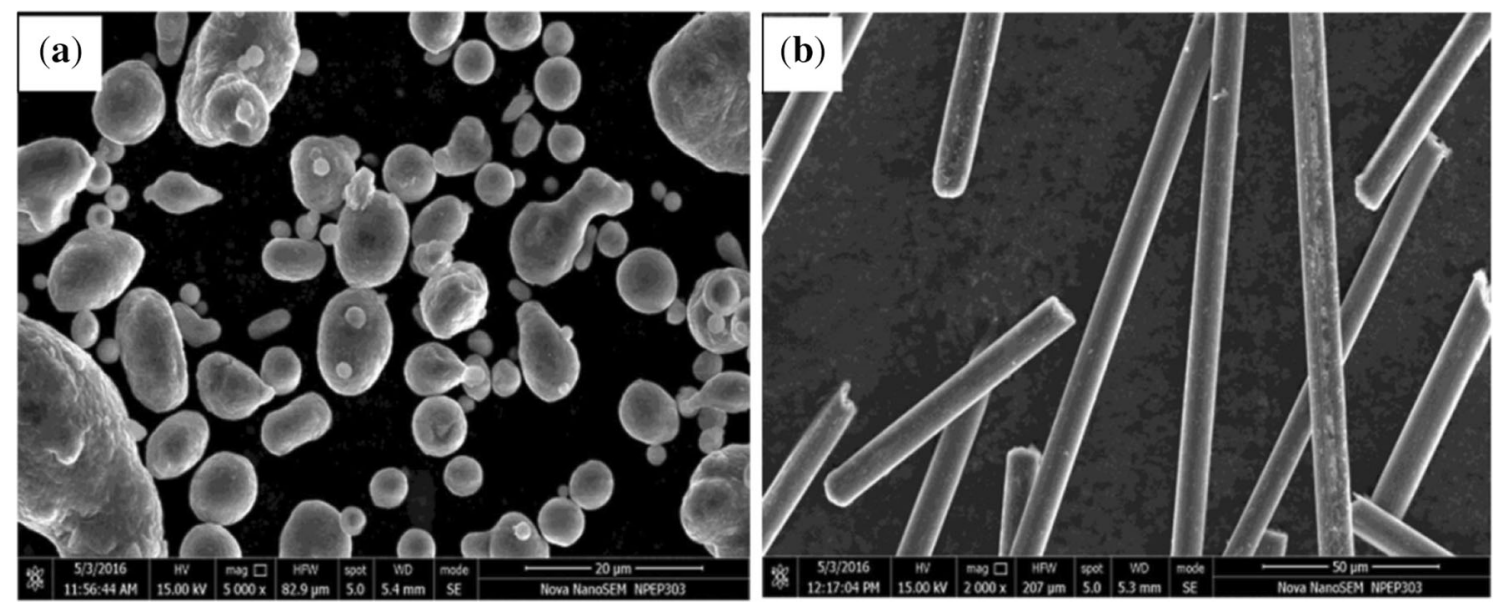

Figure 1. SEM images of as received (a) AA7075 alloy and (b) carbon fibers [14]. 
Table 2. Densities of AA7075/CF composites.

\begin{tabular}{lccc}
\hline $\begin{array}{l}\text { Composition } \\
(\text { Vol.\%) }\end{array}$ & $\begin{array}{c}\text { Density by Rule Of Mixture (ROM) } \\
(\mathrm{g} / \mathrm{cc})\end{array}$ & $\begin{array}{c}\text { Density after Hot Pressing } \\
(\mathrm{g} / \mathrm{cc})\end{array}$ & $\begin{array}{c}\text { Relative Density } \\
(\%)\end{array}$ \\
\hline Pure AA7075 & 2.81 & 2.76 & 98.22 \\
AA7075-10\%CF & 2.75 & 2.68 & 97.45 \\
AA7075-20\%CF & 2.69 & 2.61 & 97.02 \\
AA7075-30\%CF & 2.63 & 2.52 & 95.81 \\
AA7075-40\%CF & 2.57 & 2.44 & 94.94 \\
\hline
\end{tabular}

\subsection{Fabrication of the composites}

AA7075 matrix composites with pitch-based carbon fibers as the reinforcements were fabricated through the Powder Metallurgy route. Fabrication of the composites was carried out in two steps.

(a) Mixing: To obtain homogeneous mixtures containing $10,20,30$ and 40 vol.\% of carbon fibers in AA7075 powder, a laboratory mixer was used. The mixer was rotated at a low speed of $20 \mathrm{rpm}$, and the total mixing time was set to $45 \pm 5 \mathrm{~min}$.

(b) Compaction: The hot pressing of the composites was carried out using a double action press at a pressure of $50 \mathrm{MPa}$ at $580 \pm 10^{\circ} \mathrm{C}$ and under $1.8 \times 10^{-3}$ bar vacuum. Heating and cooling rates were $8^{\circ} \mathrm{C} / \mathrm{min}$ and $12^{\circ} \mathrm{C} / \mathrm{min}$, respectively. The homogenous mixture of AA7075 powder and carbon fibers was filled in the high density graphite die and consolidated by hot pressing. At the bottom and top surfaces of the powder mixture, circular graphite sheets of $0.5 \mathrm{~mm}$ thickness were placed in order to prevent adhesion between the tool and the hot-pressed specimen. Subsequently, the diepunch-powder assembly was placed inside the vacuum chamber of the hot press. Once the required temperature, vacuum and pressure were reached, the powder mixture was hot pressed. After completion of hot pressing, the whole assembly was cooled down to room temperature. Then the specimen was removed from the die, and the graphite sheets were removed from the hot pressed specimen. The entire hot pressing process for each composition took around 3 hours.

\subsection{Electro-chemical corrosion tests}

Samples for electrochemical tests were cut to 1 to $2 \mathrm{~mm}$ thick disks with $10 \mathrm{~mm}$ diameter. Samples were cut parallel to the direction of pressing so that the cross section of fiber would face the electrolyte. In order to ensure the exposure of a similar surface area to the corrosive electrolyte, samples were embedded in an epoxy resin. Current flow took place over a conducting wire which was soldered on to the back of the sample and completely covered by the epoxy resin. The embedded disks were polished to a $1 \mu \mathrm{m}$ finish. After polishing, the samples were rinsed repeatedly in distilled water and cleaned ultrasonically. Potentiodynamic corrosion tests were carried out using the Gamry Potentiostat (Gamry Instruments, Reference 600 Potentiostat / Galvanostat/2RA) in 3.5 wt. $\% \mathrm{NaCl}$ solution having $\mathrm{pH}$ 6.8. The exposed surface area of the specimen was $0.785 \mathrm{~cm}^{2}$. The specimen was arranged in a standard three electrode cell set-up. The specimen was connected to working electrode, Saturated Calomel Electrode (SCE) to reference electrode and Graphite to auxiliary electrode. The electrolyte was not agitated or aerated. Before the potentiodynamic tests, the samples were allowed to stabilize at their corrosion potential for at least 30 mins to obtain Open Circuit Potential (OCP). After this time, potentiodynamic polarization was performed with a scan rate of $1 \mathrm{mV} / \mathrm{s}$.

The parameters, corrosion potential $\left(\mathrm{E}_{\mathrm{corr}}\right)$ and corrosion current density $\left(i_{\text {corr }}\right)$ were measured in the potentiodynamic polarization study using Gamry Echem Analyst software. Tafel curves were obtained for every composition. The corrosion rates were derived from the slope of such Tafel curves. Reported results are an average of at least three corrosion tests. The reproducibility of the potentiodynamic corrosion tests is given by the standard variation. After polarization, the surfaces of the specimens were cleaned using ethanol in an ultrasonic cleaning bath. They were then examined under Scanning Electron Microscope, followed by EDS analysis.

\subsection{Scanning Electron Microscopy (SEM) and Energy Dispersive X-ray Spectroscopy (EDS)}

The specimens were cut along the parallel direction of pressing (In-Plane) and were ground and polished for metallographic studies. Composites were also observed under Zeiss scanning electron microscope equipped with EDS facility before the corrosion test, mainly to ascertain the bonding of carbon fibers with the matrix and their distribution in the matrix. SEM/EDS was carried out after the corrosion test to study corroded surface.

\subsection{Transmission Electron Microscopy (TEM) and X-Ray Diffraction (XRD)}

High Resolution Transmission Electron Microscopy (HRTEM) was employed in this investigation. For HRTEM 

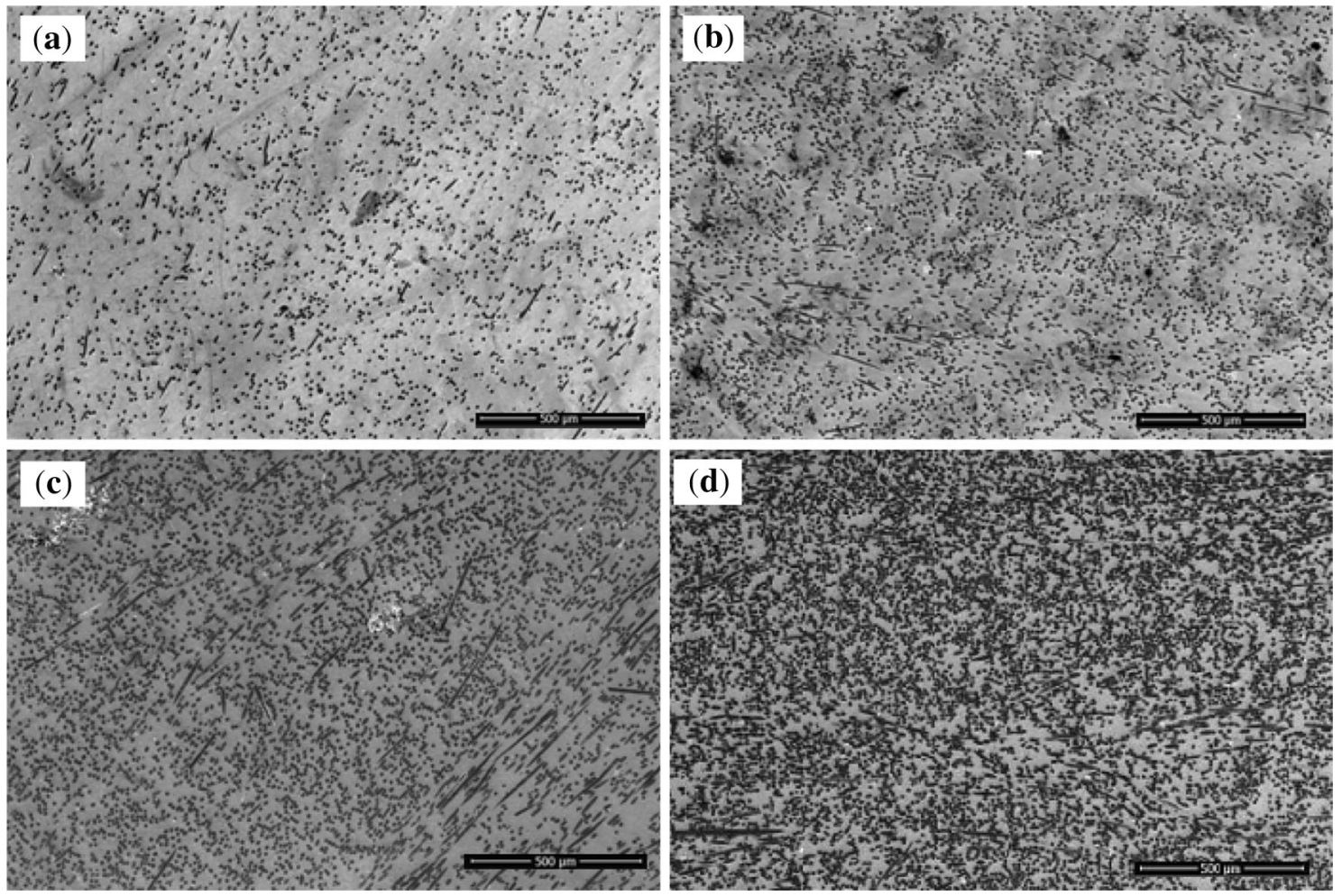

Figure 2. SEM images of parallel section of AA7075 composites with (a) 10 vol.\%, (b) 20 vol.\%, (c) 30 vol.\% and (d) 40 vol.\% of carbon fibers [14].

analysis (FEI, Tecnai G2F30), thin disks were cut from the bulk specimen 30 vol.\% and 40 vol.\% MMC, respectively. Composites with such higher carbon contents were used because the possibility of $\mathrm{Al}_{4} \mathrm{C}_{3}$, increases with fiber content. Then disks were mechanically polished to around $120 \mu \mathrm{m}$ using silicon carbide papers and diamond grinding media. Finally, thin foils of electron transparent regions were ion beam thinned with Gatan Pips Model 691. During thinning, sample rotation speed was $5 \mu \mathrm{m} / \mathrm{h}$ and milling angle was $5^{\circ}$. The thinned specimens were investigated under HRTEM. XRD was also done to confirm the absence of $\mathrm{Al}_{4} \mathrm{C}_{3}$.

\section{Results and discussion}

\subsection{Density}

Density values are given in table 2 which indicate that as carbon fiber content increases density decreases. This is because of the low density of carbon fiber compared to matrix alloy. Density of AA7075 is $2.81 \mathrm{~g} / \mathrm{cm}^{3}$ and that of pitch based carbon fibers is $1.6 \mathrm{~g} / \mathrm{cm}^{3}$ (as received from the suppliers). Thus, as amount of carbon fibers increase in the composite density of composite decreases. However, actual values of densities after hot pressing are lower than that obtained from Rule of Mixture. This low density is attributed to inherent porosity that is present in Powder Metallurgy compacts.

\subsection{TEM and XRD of MMCs before corrosion test}

Figures 2(a)-(d) show the SEM images of composites with carbon fibers of 10, 20, 30 and 40 vol.\% content before the electrochemical corrosion test. Since the images are of the section taken parallel to the pressing direction, fibers appear as black dots. Most of the fibers have arranged themselves perpendicular to the pressing direction and hence appear as black dots. However, in the specimen containing higher amounts of fibers, few fibers are seen randomly oriented as black lines.

Formation of $\mathrm{Al}_{4} \mathrm{C}_{3}$ is often observed at the interface of carbon fiber and matrix. $\mathrm{Al}_{4} \mathrm{C}_{3}$ is known to adversely affect all the properties of the MMCs. There is possibility of Crevice corrosion at the interface of MMCs with local formation of $\mathrm{Al}_{4} \mathrm{C}_{3}$ [11]. In order to verify whether it has formed, (HR) TEM and XRD examinations were carried out. Figures 3(a) and (b) display representative TEM images of $30 \mathrm{vol} \%$ and $40 \mathrm{vol} \%$ carbon fiber composites, respectively. Intimate bonding between carbon fiber with no evidence of formation of $\mathrm{Al}_{4} \mathrm{C}_{3}$ at the interface is observed. Representative XRD patterns of 10, 20 and 30 vol.\% carbon fiber composite are shown in figure 4. These patterns contain only the diffraction peaks of aluminium and graphite. No peak corresponding to $\mathrm{Al}_{4} \mathrm{C}_{3}$ is seen.

Thus from TEM images and XRD patterns it is confirmed that $\mathrm{Al}_{4} \mathrm{C}_{3}$ is not formed at the interface of carbon fiber and matrix. 

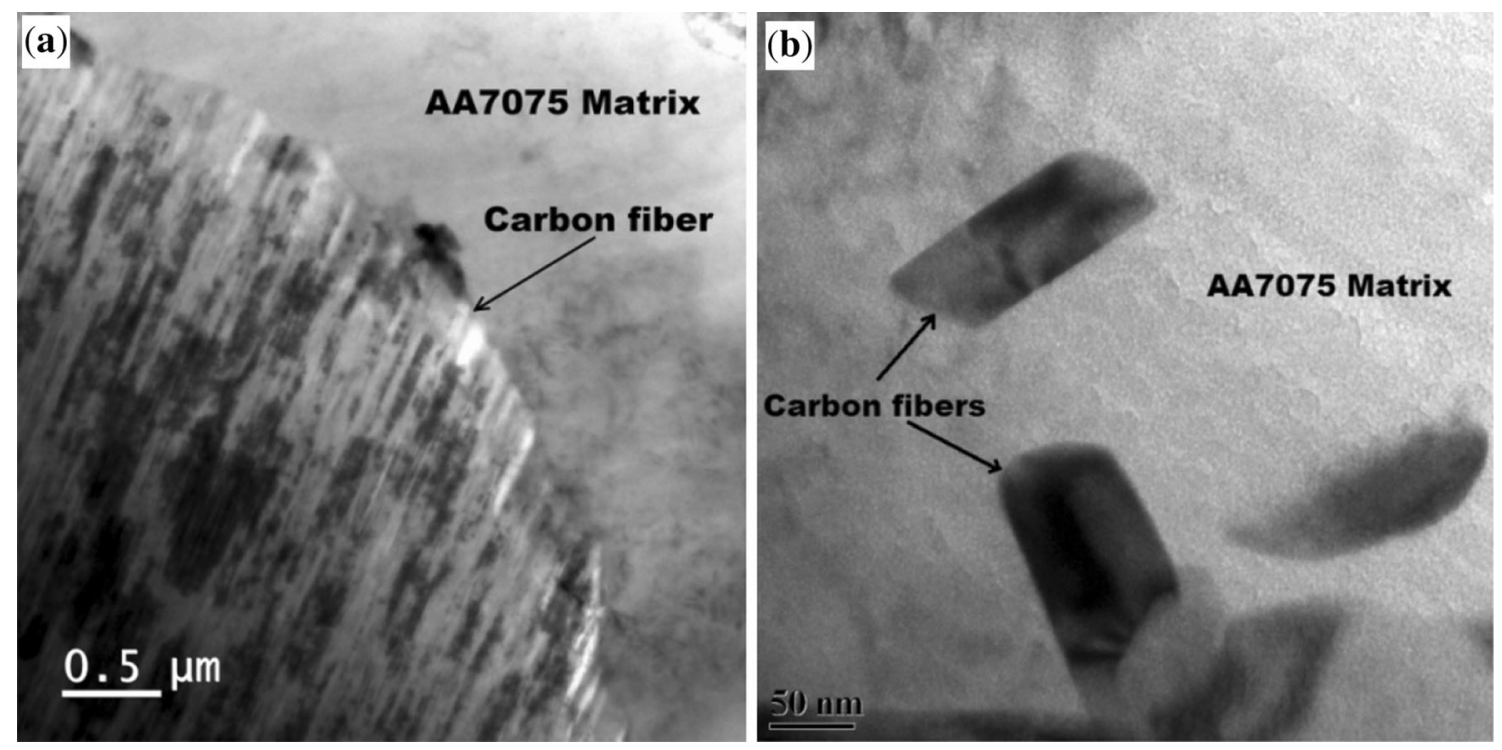

Figure 3. Transmission electron micrograph of composites containing (a) 30 vol. $\%$ and (b) 40 vol. $\%$ carbon fibers.

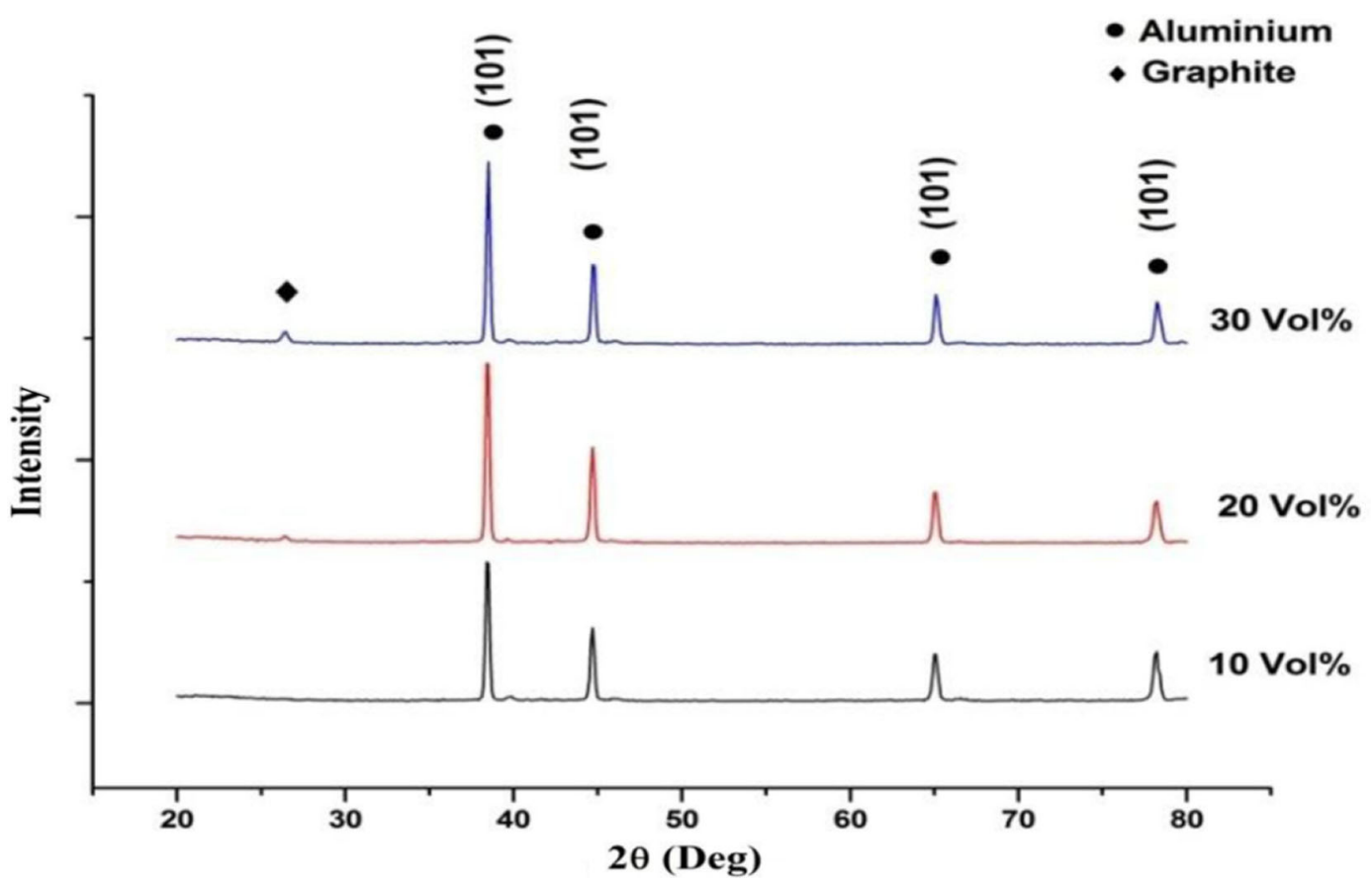

Figure 4. XRD analysis of composites containing 10, 20 and 30 vol.\% carbon fibers [14].

\subsection{Observations after the electrochemical corrosion tests}

Table 3 shows the results of potentiodynamic corrosion test in $3.5 \mathrm{wt} \% \mathrm{NaCl}$ aqueous solution. It is seen from table that $i_{\text {corr }}$ value of composite with carbon fibers is much more as compared to that of pure AA7075. Due to the absence of carbon fibers (and hence due to the absence of galvanic cells), corrosion rate is low in the pure AA7075. In the case of the composites, carbon fibers readily form galvanic cell with the matrix (because these are cathodic with respect to aluminium matrix) that leads to corrosion at the interface. As the carbon fibers amount increases, the corrosion potential $\mathrm{E}_{\mathrm{corr}}$ shifts to the negative direction, and the corrosion current density $i_{\text {corr }}$ increases. Corrosion rate is obtained from the slope of Tafel curves of the respective composition (comparison of Tafel curves for all composites is shown in figure 5).

It follows from table 3 that as the amount of carbon fiber content increases from 0 to $40 \mathrm{vol} . \%$, corrosion potential 
Table 3. Results of electrochemical test.

\begin{tabular}{lccr}
\hline $\begin{array}{l}\text { Composition } \\
\text { (Vol.\%) }\end{array}$ & $\begin{array}{c}\text { Corrosion Potential } \\
\mathrm{E}_{\text {corr }}(\mathrm{mV})\end{array}$ & $\begin{array}{c}\text { Corrosion current density } \\
i_{\text {corr }}\left(\mu \mathrm{A} / \mathrm{cm}^{2}\right)\end{array}$ & $\begin{array}{c}\text { Corrosion rate } \\
\text { Mils per year }(\mathrm{mpy})\end{array}$ \\
\hline Pure AA7075 & -440.12 & 3.37 & $1.29 \pm 0.523$ \\
AA7075-10\%CF & -611.56 & 33.86 & $13.00 \pm 1.236$ \\
AA7075-20\%CF & -760.86 & 45.30 & $20.02 \pm 2.158$ \\
AA7075-30\%CF & -813.15 & 48.37 & $23.90 \pm 2.534$ \\
AA7075-40\%CF & -895.35 & 72.15 & $43.67 \pm 2.743$ \\
\hline
\end{tabular}

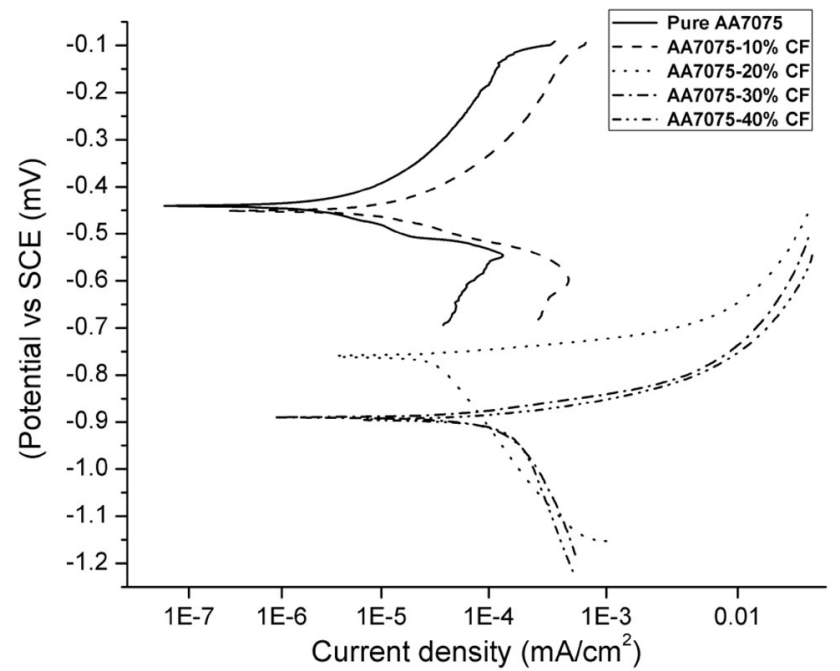

Figure 5. Tafel curves for pure AA7075 and composite with 10, 20,30 and 40 vol. $\%$ carbon fibers.

$\mathrm{E}_{\text {corr }}$ changes from $-440.12 \mathrm{mV}$ to $-895.35 \mathrm{mV}$ i.e., it becomes more and more anodic. Corrosion current density, $i_{\text {corr }}$ increases from $3.37 \mu \mathrm{A} / \mathrm{cm}^{2}$ to $43.67 \mu \mathrm{A} / \mathrm{cm}^{2}$. This leads to increase in corrosion rate from $1.29 \mathrm{mpy}$ to $43.67 \mathrm{mpy}$ as fiber content goes on increasing from 0 to 40 vol. $\%$.

Suggested explanation for this is as amount of carbon fibers increases, more and more interfaces are created. This causes galvanic corrosion between carbon fiber and matrix at the interfaces. Increased number of galvanic cells consequently cause increase in corrosion rate. This is evidenced in SEM images of the composites taken after corrosion tests, given in figures 7-9. It follows from these images that deterioration of composite after corrosion test, seems to be more and more as fiber content goes on increasing.

Figure 5 shows Tafel curves for all composites i.e., from pure AA7075 to composite with 40 vol.\% carbon fibers. It is clear from these curves that as amount of carbon fiber content goes on increasing, the curves shift away from $\mathrm{Y}$ axis i.e., corrosion current density $i_{\text {corr }}$ increases. Tafel curve for pure AA7075 is nearest to $\mathrm{Y}$ axis showing lowest corrosion rate, 1.29 mpy. Tafel curve of composite with 40 vol.\% carbon fibers is farthest from $\mathrm{Y}$ axis showing highest corrosion current density and thus highest corrosion rate. It is also observed that Tafel curves shift downwards with increase in carbon fiber content. It means that corrosion potential $\mathrm{E}_{\text {corr }}$ becomes more and more negative. This causes more and more corrosion as fiber content goes on increasing. Though Tafel curves of composites with 30 and 40 vol.\% carbon fibers seem to be overlapping, but Tafel curve of composite with 40 vol.\% carbon fibers is farthest away from $\mathrm{Y}$ axis and shifted downwards most, exhibiting highest corrosion rate, $43.67 \mathrm{mpy}$ as against $23.9 \mathrm{mpy}$ in case of composite with 30 vol.\% carbon fibers.
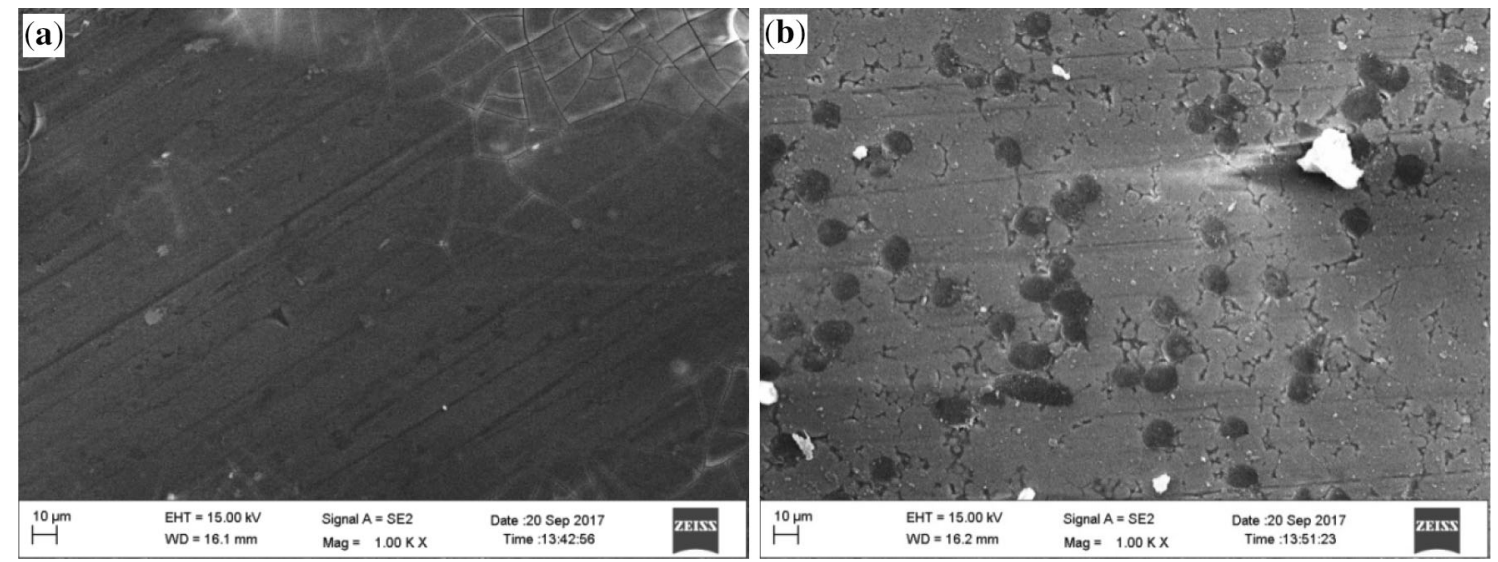

Figure 6. SEM after corrosion test (a) pure AA7075 and (b) composite with 10 vol.\% carbon fiber. 

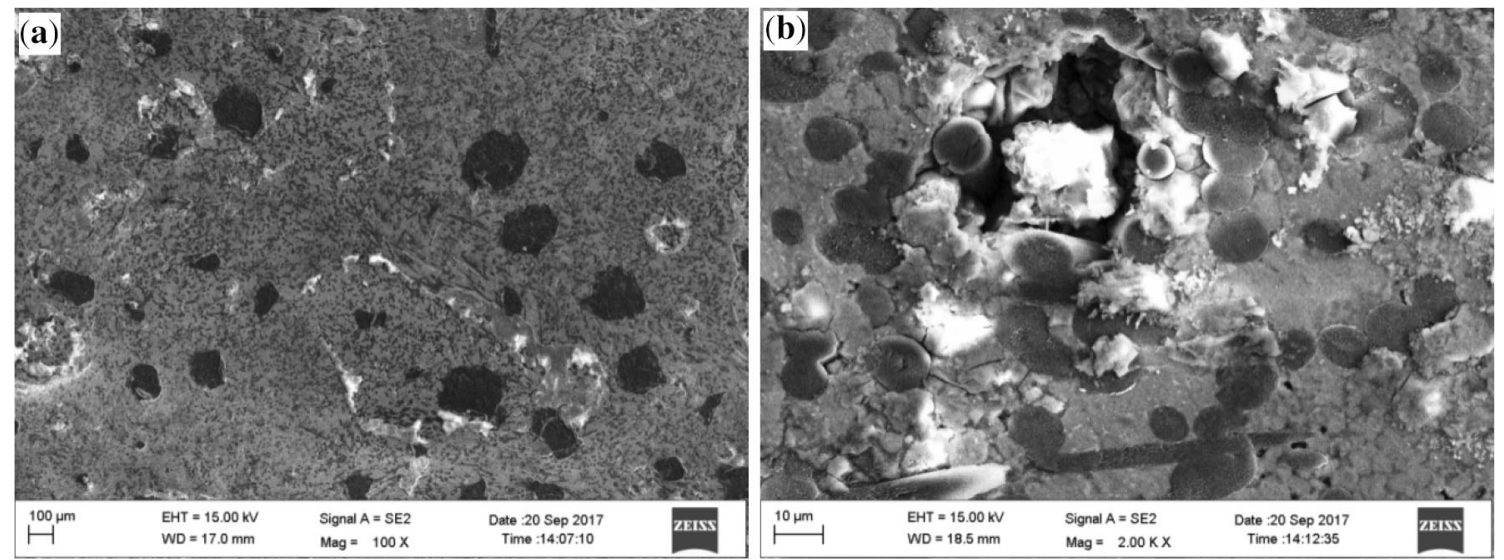

Figure 7. SEM after corrosion test composite with (a) 20 vol. $\%$ and (b) 30 vol. $\%$ carbon fibers.

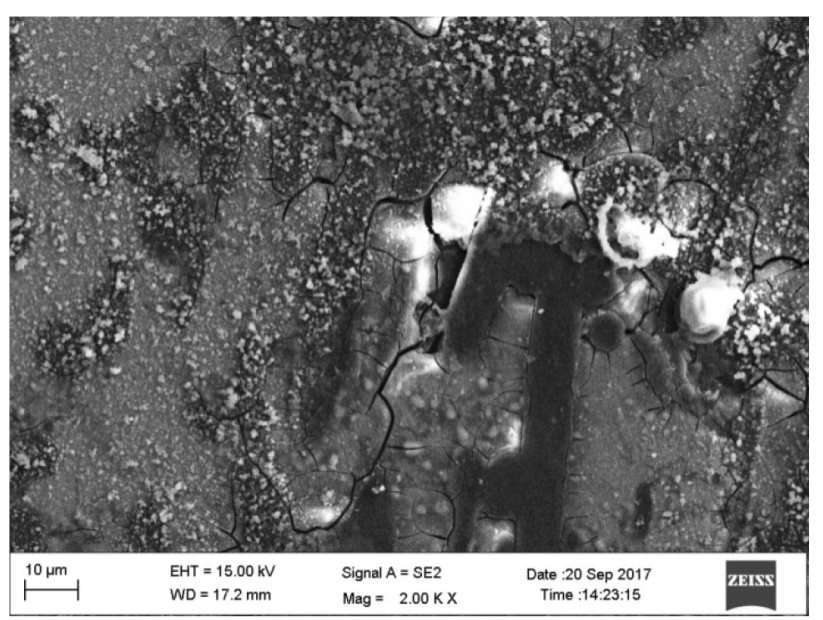

Figure 8. SEM after corrosion test of composite with 40 vol.\% carbon fibers.

Corrosion results indicate that corrosion rate increases steadily with increase in carbon fiber content till $30 \mathrm{vol} \%$ of carbon fibers. Sudden rise in corrosion rate for $40 \mathrm{vol} . \%$ carbon fiber composite is explained in the next section referring to respective composites SEM/EDS analysis.

\subsection{SEM Analysis}

Figures 6-8 show the SEM images of the composites after the electrochemical test. Deterioration of the matrix increases as the amount of carbon fiber content increases. Galvanic cell forms at the interface of carbon fiber and matrix. Matrix dissolution is seen around carbon fiber, as the matrix is anodic to carbon fiber (electrode potential of carbon fiber is $+0.207 \mathrm{~V}$ and that of aluminium matrix is $-1.66 \mathrm{~V})$.With increased carbon fiber content, more number of galvanic cells are formed. Cracks in the matrix seem to be increasing with the amount of carbon fibers.

The composites used in the present study have been manufactured by Powder Metallurgy technique. Due to this, heterogeneity and porosity is inevitable in the specimens, which is likely to increase as amount of carbon fibers increases. Composite with 40 vol.\% of carbon fibers may have porosity and bonding of the fibers with the matrix may be weak due to higher amount of carbon fibers. These

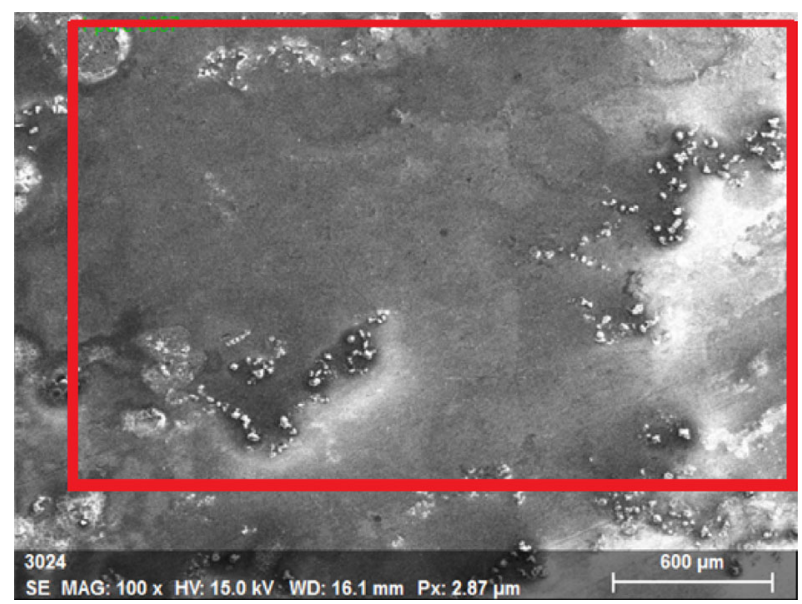

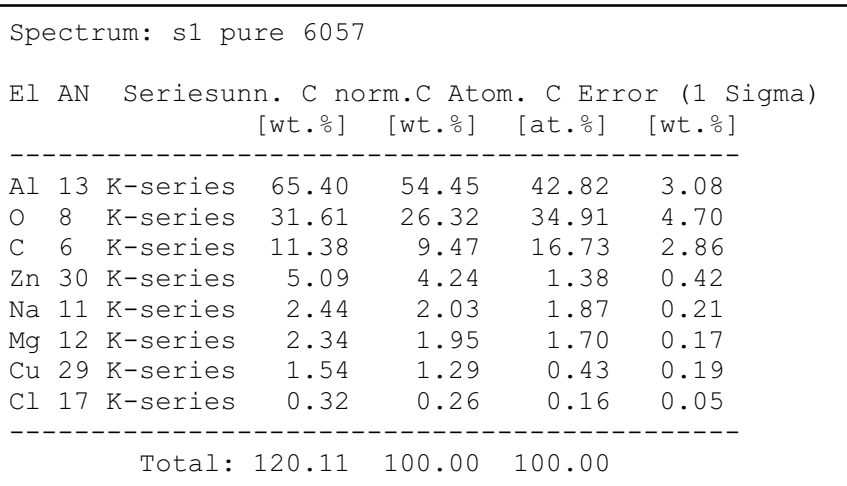

Figure 9. SEM/EDS of pure AA7075. 


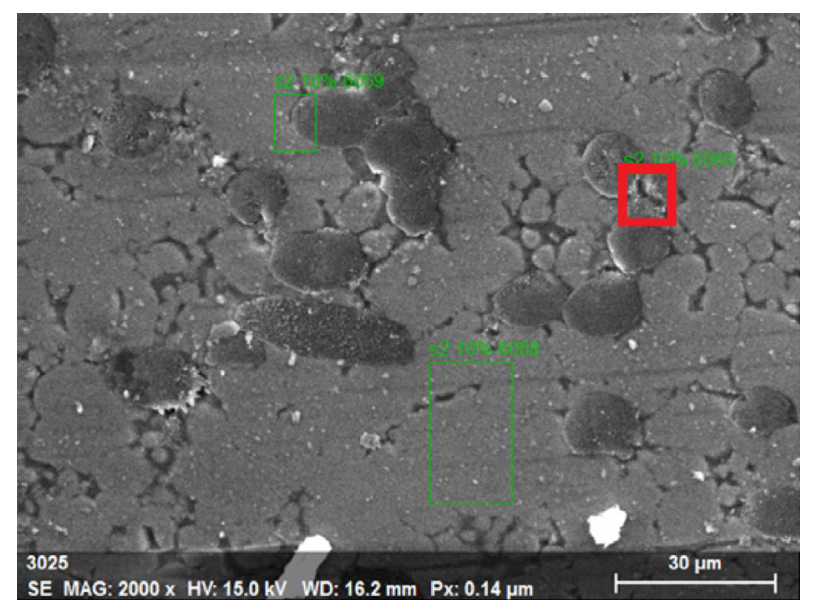

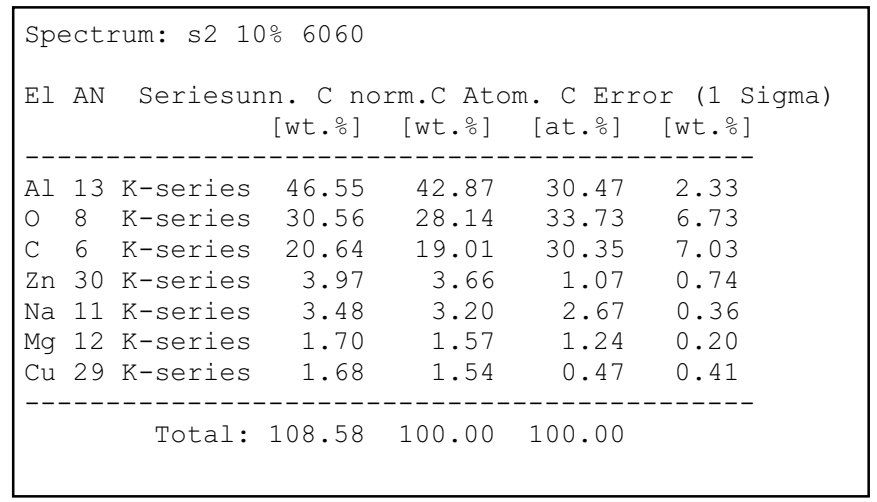

Figure 10. SEM/EDS of composite with 10 vol. $\%$ carbon fibers.

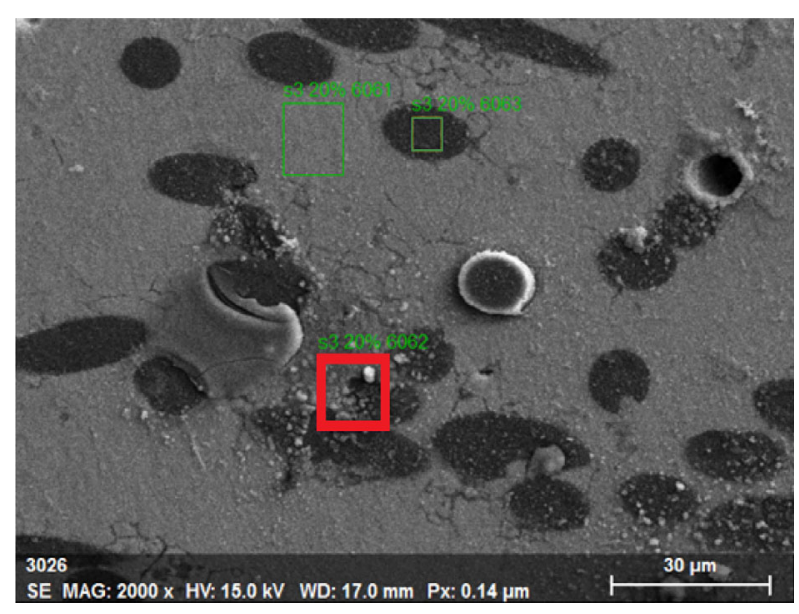

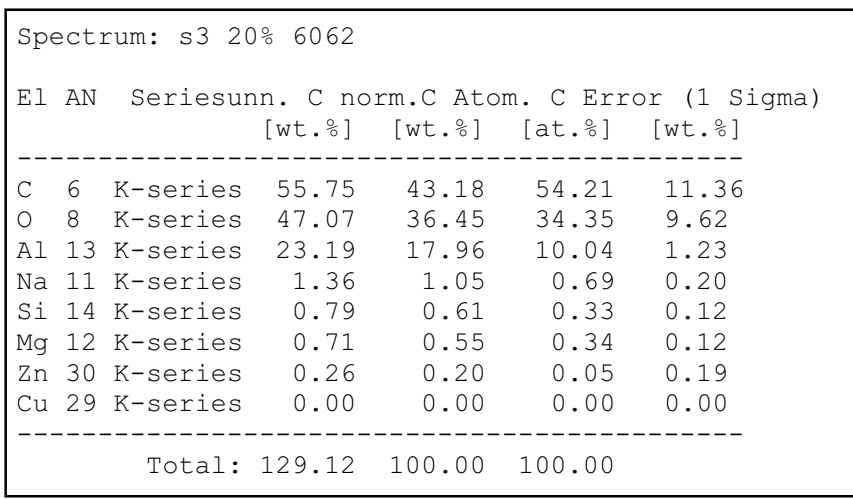

Figure 11. SEM/EDS of composite with 20 vol. $\%$ carbon fibers.

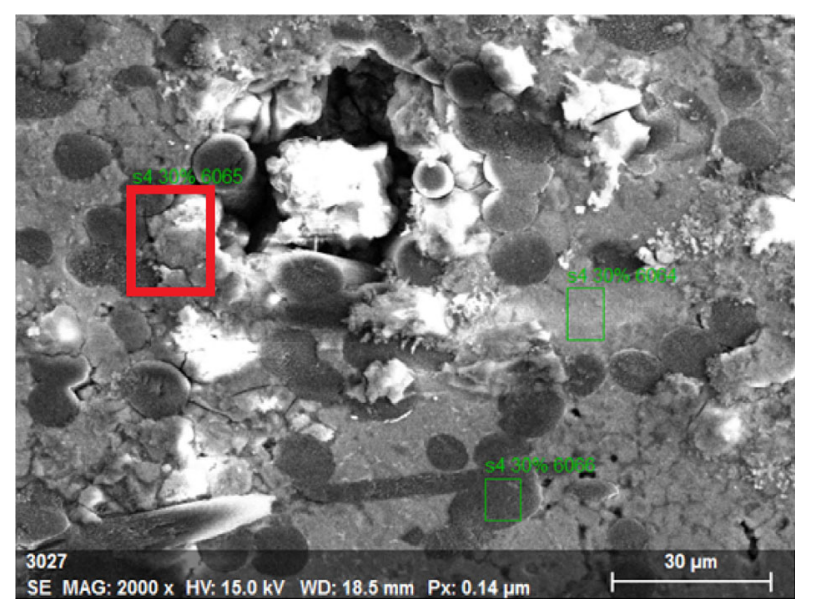

\begin{tabular}{|c|c|c|c|c|c|c|}
\hline \multicolumn{7}{|c|}{ Spectrum: s4 $30 \% 6065$} \\
\hline \multicolumn{2}{|c|}{ El AN } & \multicolumn{5}{|c|}{ 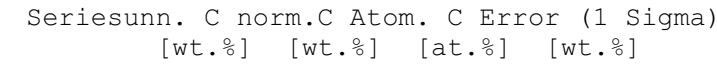 } \\
\hline 0 & 8 & K-series & 57.82 & 40.93 & 46.58 & 8.06 \\
\hline Al & 13 & K-series & 48.94 & 34.65 & 23.38 & 2.32 \\
\hline $\mathrm{C}$ & 6 & K-series & 25.26 & 17.88 & 27.11 & 4.94 \\
\hline $\mathrm{Zn}$ & 30 & K-series & 4.38 & 3.10 & 0.86 & 0.42 \\
\hline $\mathrm{Na}$ & 11 & K-series & 1.71 & 1.21 & 0.96 & 0.17 \\
\hline $\mathrm{Cu}$ & 29 & K-series & 1.42 & 1.01 & 0.29 & 0.20 \\
\hline Mg & 12 & K-series & 1.18 & 0.83 & 0.62 & 0.11 \\
\hline $\mathrm{Cl}$ & 17 & K-series & 0.55 & 0.39 & 0.20 & 0.07 \\
\hline & & Total: & 141.26 & 100.00 & 100.00 & \\
\hline
\end{tabular}

Figure 12. SEM/EDS of composite with 30 vol. $\%$ carbon fibers. 


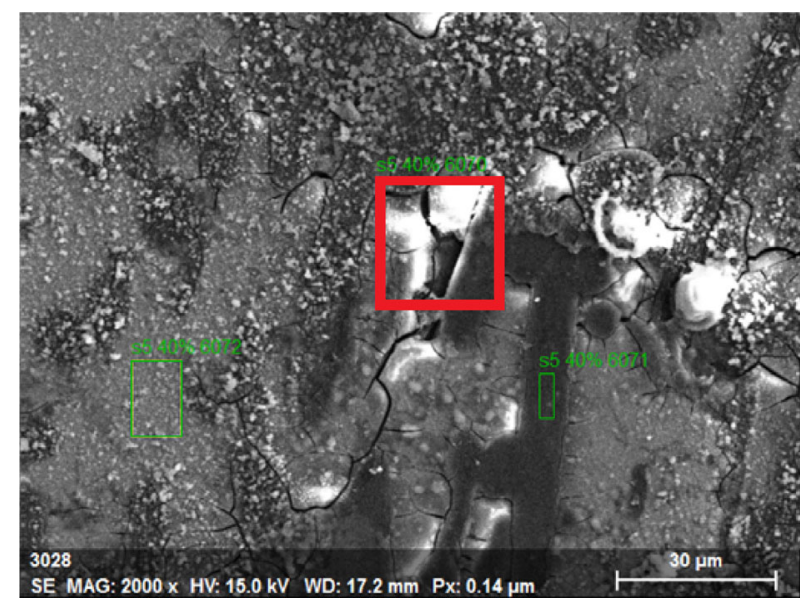

\begin{tabular}{|c|c|c|c|c|c|c|}
\hline \multicolumn{7}{|c|}{ Spectrum: s5 $40 \% 6070$} \\
\hline \multicolumn{7}{|c|}{$\begin{array}{l}\text { El AN Series unn. C norm.C Atom. C Error (1 Sigma) } \\
[\text { wt. \% }][\text { wt. \% }][\text { at. \% }] \text { [wt.\% }]\end{array}$} \\
\hline 0 & 8 & K-series & 68.36 & 47.85 & 44.99 & 9.03 \\
\hline $\mathrm{C}$ & 6 & K-series & 53.95 & 37.76 & 47.29 & 7.48 \\
\hline Al & 13 & K-series & 15.09 & 10.56 & 5.89 & 0.75 \\
\hline $\mathrm{Na}$ & 11 & K-series & 2.44 & 1.71 & 1.12 & 0.21 \\
\hline $\mathrm{Zn}$ & 30 & K-series & 1.53 & 1.07 & 0.25 & 0.20 \\
\hline $\mathrm{Mg}$ & 12 & K-series & 0.78 & 0.55 & 0.34 & 0.08 \\
\hline $\mathrm{Cu}$ & 29 & K-series & 0.59 & 0.41 & 0.10 & 0.11 \\
\hline $\mathrm{Cl}$ & 17 & K-series & 0.11 & 0.08 & 0.03 & 0.04 \\
\hline & & Total: & 142.86 & 100.00 & 100.00 & \\
\hline
\end{tabular}

Figure 13. SEM/EDS of composite with 40 vol. $\%$ carbon fibers.

reasons contribute to sudden rise in the corrosion rate of composite with 40 vol.\% carbon fibers.

\subsection{SEM /EDS Analysis}

EDS analysis was carried out at various locations of the specimens after the corrosion trials. Representative EDS images are given in figures 9-13, locations where EDS was carried out were shown in thick red box. The white portions in the images correspond to $\mathrm{NaCl}$. It follows from this analysis that oxygen concentration increases at the interface of carbon fiber and the matrix as vol.\% of carbon fibers increase. In composite material, if reinforcement is conducting and nobler than matrix material, galvanic corrosion is inevitable which increases with increase in the amount of reinforcement [15]. In the current work, carbon fibers being nobler, matrix is dissolved forming pits at the interface. This is explained in section 3.3 also. Galvanic corrosion in the composite used in this study is manifested by increase in oxygen concentration at the interface with increase in vol. \% of carbon fibers.

\section{Conclusions}

The electrochemical behavior of milled carbon fiber reinforced AA7075 was investigated in this work, with the objective of assessing the suitability of these MMCs in corrosive atmosphere. Following inferences are drawn from the study.

- Due to increase in carbon fiber content, density of composites decreases. Theoretical densities could not be achieved as composites were manufactured by Powder Metallurgy route.

- The processing technique adopted for producing the MMCs too has a pronounced effect on the corrosion behavior. The powder metallurgy route adopted in this work resulted in the total absence of $\mathrm{Al}_{4} \mathrm{C}_{3}$ which causes corrosion.

- The bonding of carbon fiber with the matrix plays an important role in the number of galvanic cells that are formed and hence on the corrosion behavior.

- Corrosion current density $i_{\text {corr }}$ (determined by Tafel extrapolation method) rises on incorporating carbon fibers. Steady increase in $i_{\text {corr }}$ is seen in composite with carbon fiber content up to 30 vol. $\%$. Sudden rise in corrosion rate is observed in composite with $40 \mathrm{vol} \%$ carbon fiber content. Thus, it is evident that the addition of carbon fibers (up to $40 \mathrm{vol} \%$ content studied in this work) enhances the corrosion rate.

- The fact that corrosion is due to the selective dissolution of matrix near the carbon fibers (which is due to presence of oxygen) is evidenced by the EDX profile analysis. Essentially, oxygen content increases at the interface of carbon fiber and matrix, so as the carbon fiber amount increases, corrosion rate increases.

- It is obvious from this study that in the industrially important aluminum alloy AA7075, the incorporation of carbon fiber reinforcements adversely affects the corrosion resistance (although such additions have been reported to improve the mechanical properties and the thermal properties). Therefore, due precaution is needed while selecting such MMCs for thermal management applications.

\section{References}

[1] Silvain S J F, Veillere A and Lu Y 2014 Copper-carbon and aluminium-carbon composites fabricated by powder metallurgy. J. Phys. Confer. Ser. 525: 12-15

[2] Chen J K and Huang I S 2013 Thermal properties of aluminum-graphite composites by powder metallurgy. Compos. Part B 44: 698-703 
[3] Winkler S L and Flower H M 2014 Stress corrosion cracking of cast 7XXX aluminium fiber reinforced composites. Corros. Sci. 46: 903-915

[4] Bakkar A and Ataya S 2014 Corrosion behavior of stainless steel fiber-reinforced copper metal matrix composite with reference to electrochemical response of its constituents. Corros. Sci. 85: 343-351

[5] Mathan Kumar N, Kumaran S S and Kumaraswamidhas L A 2015 An investigation of mechanical properties and corrosion resistance of Al2618 alloy reinforced with $\mathrm{Si}_{3} \mathrm{~N}_{4}, \mathrm{AlN}$ and $\mathrm{ZrB}_{2}$ composites. J. Alloys Compd. 652: 244-249

[6] Verma A S, Sumankant, Suri N M and Yashpal 2015 Corrosion behavior of aluminum base particulate metal matrix composites: a review. Mater. Today Proc. 2: 2840-2851

[7] Naji H, Zebarjad S M and Sajjadi S A 2008 The effects of volume percent and aspect ratio of carbon fiber on fracture toughness of reinforced aluminum matrix composites. Mater. Sci. Eng. 486(1-2): 413-419

[8] Sánchez M, Rams J and Ureña A 2010 Fabrication of aluminium composites reinforced with carbon fibers by a centrifugal infiltration process. Compos. Part A 41: 1605-1611

[9] Bhav Singh B and Balasubramanian M 2009 Processing and properties of copper-coated carbon fiber reinforced aluminium alloy composites. J. Mater. Process. Technol. 209: 2104-2110

[10] Lee M, Choi Y, Sugio K, Matsugi K and Sasaki G 2014 Effect of aluminium carbide on thermal conductivity of the unidirectional $\mathrm{CF} / \mathrm{Al}$ composites fabricated by low pressure infiltration process. Compos. Sci. Technol. 97: 1-5

[11] Wielage B and Dornar A 1999 Corrosion studies on aluminium reinforced with uncoated and coated carbon fibers. Compos. Sci. Technol. 59: 1239-1245

[12] Bhagat R B, Amateau M F, Paulik J M., Chrisholm J M, Parnell J M, Seidensticker D G 1988 In: Fishman S G and Dhingra A K (eds) Cast reinforced metal composites. USA: ASM Inter-national, pp. 185-194

[13] Simancik E, Jangg G and Degischer H 1993 Short carbon fiber-aluminium matrix composite material prepared by extrusion of powder mixtures. Journal De Physique IV Colloque 3(C7): C7-1775-C7-1780

[14] Deshpande M, Gondil R, Narayan Murty S V S and Kalal R K 2017 Studies on 7075 aluminium alloy MMCs with milled carbon fibers as reinforcements. Trans. Indian Inst. Metals 71(4): 993-1002

[15] Hihara L H and Bakkar A 2016 Corrosion of metal matrix composites. In: Reference Module in Materials Science and Materials Engineering pp. 1-28 